\title{
In-vivo Assessment of Neuropharmacological Activity of Methanol Bark Extract of Mimosa pudica in Mice
}

\author{
Lokman Hossain ${ }^{1, *}$, Sharmin Sultana ${ }^{2}$ \\ ${ }^{1}$ Department of Pharmacy, Stamford University Bangladesh, Bangladesh \\ ${ }^{2}$ Pharmacy Discipline, Life Science School, Khulna University, Bangladesh
}

Copyright $(2019$ by authors, all rights reserved. Authors agree that this article remains permanently open access under the terms of the Creative Commons Attribution License 4.0 International License

\begin{abstract}
Background: Mimosa pudica, a common plant of Mimosoideae family has been used as Ayurvedic herbal medicine by Bangladeshi and Chinese to treat several diseases such as hemorrhoids, hair loss, arthritis, dysentery, leprosy, jaundice, leukoderma, asthma, uterine problems. The root and bark of the plant is said to display antimicrobial activity. Hence, gargling with a decoction of the root and bark of Mimosa pudica diluted in water may help to treat toothaches. Aim of the study: The present study was designed to evaluate the presence of phytochemical groups and to investigate the neuropharmacological activity of methanol extract of Mimosa pudica (MEMP). Methodology: The neuropharmacological activity was determined by hole cross and open field test using Swiss Albino mice as experimental animal. Results: Phytochemical analysis of Mimosa pudica extract indicated the presence of tannins, alkaloids, terpenoids and flavonoids. The sample showed dose-dependent sedative activity at the doses of 200 and $400 \mathrm{mg} / \mathrm{kg}$ body weight compared to standard drug Diazepam (1 mg/kg body weight). Conclusion: MEMP showed significant sedative activity demonstrating that the extract may be useful in the development of a new sedative and anti-anxiety drug.
\end{abstract}

Keywords Mimosa pudica, Swiss Albino Mice, Neuropharmacological Activity, Hole Cross Test, Open Field Test

\section{Introduction}

According to The World Health Organization, depression is among the top ten causes of morbidity, and mortality world over [1], and it is envisaged to be the leading cause of morbidity and mortality by the year 2030 [2]. Patients with depression have symptoms that reflect a functional deficit in brain monoamine neurotransmitters, specifically norepinephrine, serotonergic and dopaminergic systems [3]. Other neurotransmitters such as GABA acting via GABAB receptor, $\beta$ adrenoceptors, muscarinic cholinergic receptor, glutaminergic via NMDA receptor $[4,5]$, and nitric oxide signaling pathways have been implicated in depression.

Despite the availability of synthetic antidepressant drugs, depression remains a major medical problem [6]. This is because the currently available antidepressant drugs are associated with a numerous side effects which include weight gain, hypopiesia, sexual dysfunction, cardiac toxicity and sleep disorder [7-9]. Therefore, herbal therapies should be considered alternative or complementary medicines [10].

Mimosa pudica commonly called sensitive plant, sleepy plant, Dormilones, touch-me-not, or shy plant is a creeping annual or perennial herb that is found to be useful in alleviating the symptoms of hemorrhoids. The herb is said to act as a natural astringent, displays antiseptic properties, and is said to impart a cooling effect. Mimosa pudica is thought to encourage new hair cell growth, which may contribute in arresting hair loss. It exhibits styptic activity, which can also help to stop bleeding in wounds and medical conditions like ulcerative colitis and menorrhagia. This plant is said to display anti-inflammatory activity, which may aid to treat inflammatory conditions like arthritis. So, those suffering from swollen joints may get relief by daily taking 1-3 $\mathrm{mL}$ tincture of $M$. pudica diluted with water. Another option is to daily drink a cup of herbal tea made from the leaves of this plant [11]. Taking a decoction of the root of Mimosa pudica may be helpful for the treatment of urinary infections, particularly bladder stones [12].

Plants belonging to Mimosoideae family have been used for the common ailments as traditional medicine. Recent research has now indicated that these herbs are a rich source of phenolic phytochemicals having high antioxidant activity. Phenolic phytochemicals are now implicated to have the potential for the management of many chronic diseases such as diabetes and cardiovascular diseases [13]. 
Due to some side effects of synthetic drugs, a continuous search for new affordable therapeutic agents with minimal side effects from medicinal plants is imperative. The objective of this study was to investigate the sedative and anti-anxiety effect of the stem bark extract using cold extraction protocol.

\section{Materials and Methods}

\subsection{Plant Materials}

A comprehensive review was conducted for the selection of the plant. Then the plant bark was collected from Shukundi, Narsingdi, Dhaka, Bangladesh in August 2017. Later on the plant was identified and verified by the senior scientific officer of Bangladesh National herbarium, Mirpur, Dhaka and the given accession code was DACB: 45374. Additionally, the voucher specimen number deposited for further reference.

\subsection{Preparation of Plant Extract}

The Powdered dried bark of Mimosa pudica of $350 \mathrm{gm}$ was taken in a clean and flat-bottomed glass beaker and soaked in $5000 \mathrm{~mL}$ methanol (95\%) (Merck, Germany) at $25 \pm 2^{\circ} \mathrm{C}$ for seven days accompanying regular shaking and stirring. After seven days, the solvent mixture was filtrated by a piece of sterile and white cotton material and finally using Whatman No. 1 filter paper. The solvent was completely removed by the operation of the rotary evaporator (BC-R201 Shanghai Biochemical Equipment Co. Ltd.) and obtained 12.75 gm extract (Yield 3.64\%). The prepared extract was used for the phytochemical screening as well as pharmacological studies

\subsection{Chemicals and Drugs}

Chemicals and drugs used in our study: Methanol (Merck, Germany), Diazepam (Square Pharmaceuticals Ltd., Bangladesh). MEMP at the doses of 200 and 400 $\mathrm{mg} / \mathrm{kg}$ dissolved in distilled water and administered orally 30 minutes before to the test.

\subsection{Animals and Ethical Approval}

Swiss albino mice (20-25 gm) of both sex were collected from the animal research branch of the International Center for Diarrheal Disease and Research, Bangladesh (ICDDR, B). The animals were kept under standard laboratory conditions as well as maintained room temperature, relative humidity: $55-65 \%, 12$ hours light/dark cycle with standard diet. We followed Ethical Principles and Guidelines for mice an observation which was provided by Scientific Experiments on Animals. This guideline was generated by Swiss Academy of Medical
Sciences and Swiss Academy of Science. Our research activities were approved by the Animal Ethical Committee (SUB/IAEC/15.04) of Stamford University Bangladesh.

\subsection{Phytochemical Screening}

The crude methanol extract of $M$. pudica bark was qualitatively tested for the detection of alkaloids, glycosides, flavonoids, tannins, reducing sugar, carbohydrates, steroids and saponins following standard procedures [14].

\subsection{Neuropharmacological Activity Test}

\subsubsection{Hole Cross Test}

The hole cross test was carried out by the method described by Basak A. et al. (2016) [15]. A steel partition was fixed in the middle of a cage having a size of $30 \times 20 \times 14 \mathrm{~cm}$. A hole of $3 \mathrm{~cm}$ diameter was made at a height of $7.5 \mathrm{~cm}$ in the center of the cage. The animals were divided into control, positive control, and two test groups containing 5 mice each. The test groups were given sample at the doses of 200 and $400 \mathrm{mg} / \mathrm{kg}$ body weight orally whereas the control groups received vehicle ( $1 \%$ Tween 80 in water) and the positive control group was given diazepam ( $1 \mathrm{mg} / \mathrm{kg}$ body weight). The number of passage of mouse through the hole from one chamber to other was counted for a period of $3 \mathrm{~min}$ at $0,30,60$, and 90 minutes after oral administration of vehicle, sample and standard drug.

\subsubsection{Open Field Test}

In open field test, the animals were divided into control, positive control, and two test groups containing 5 mice each of both sex. The test groups were given M. pudica extract at the doses of 200 and $400 \mathrm{mg} / \mathrm{kg}$ body weight orally. The control group was administered vehicle (1\%Tween 80 in water) at the dose of $0.1 \mathrm{~mL} /$ mouse and the positive control group was treated with diazepam at the dose of $1 \mathrm{mg} / \mathrm{kg}$ body weight [16, 17]. The floor of an open field of half square meter was divided into series of squares each alternatively colored black and white. The apparatus had a wall of $40 \mathrm{~cm}$ height. The number of squares visited by the animals was counted for 3 minute at $0,30,60$, and 90 minutes after oral administration of the test sample, control and the standard.

\subsection{Statistical Analysis}

The experimental data were expressed as mean \pm SEM. The significance of difference among the various treated groups and control group were analyzed by means of one-way ANOVA followed by Dunnett's multiple comparison tests. A $\mathrm{p}<0.05$ was considered statistically significant. 
Table 1. Effect of M. pudica extract in hole cross test on mice

\begin{tabular}{cccccc}
\hline \multirow{2}{*}{ Treatment } & Dose (mg/kg b.w.) & \multicolumn{4}{c}{ Number of Movement } \\
\cline { 3 - 6 } & & $0 \mathrm{~min}$ & $30 \mathrm{~min}$ & $60 \min$ & $90 \mathrm{~min}$ \\
\hline Control & $0.1 \mathrm{~mL} / \mathrm{mouse}$ & $60.8 \pm 1.01$ & $53.4 \pm 0.92$ & $46 \pm 0.82$ & $34.2 \pm 1.01$ \\
\hline Diazepam & $1 \mathrm{mg} / \mathrm{kg}$ b.w. & $44.2 \pm 0.74$ & $29.2 \pm 0.50$ & $14.4 \pm 0.37$ & $18.8 \pm 0.83$ \\
\hline Group-I & $200 \mathrm{mg} / \mathrm{kg}$ b.w. & $59.5 \pm 0.85$ & $40.8 \pm 0.55$ & $30.4 \pm 0.44$ & $32 \pm 0.69$ \\
\hline Group-II & $400 \mathrm{mg} / \mathrm{kg}$ b.w. & $54.2 \pm 0.85$ & $34.8 \pm 0.55$ & $20.4 \pm 0.44$ & $25 \pm 0.69$ \\
\hline
\end{tabular}

Values are expressed as Mean $\pm \operatorname{SEM}(\mathrm{n}=5)$;

$* \mathrm{P}<0.05$ compared with the control group (Dunnett's Test)

Table 2. Effect of M. pudica extract in open field test on mice

\begin{tabular}{cccccc}
\hline \multirow{2}{*}{ Treatment } & Dose $(\mathrm{mg} / \mathrm{kg}$ b.w.) & \multicolumn{4}{c}{ Number of Movement } \\
\cline { 3 - 6 } & & $0 \mathrm{~min}$ & $30 \mathrm{~min}$ & $60 \min$ & $90 \mathrm{~min}$ \\
\hline Control & $0.1 \mathrm{~mL} / \mathrm{mouse}$ & $105.3 \pm 1.12$ & $93.6 \pm 1.01$ & $96.8 \pm 0.96$ & $101.2 \pm 1.12$ \\
\hline Diazepam & $1 \mathrm{mg} / \mathrm{kg}$ b.w. & $74.2 \pm 0.66$ & $49.2 \pm 0.59$ & $24.4 \pm 0.44$ & $28.8 \pm 0.64$ \\
\hline Group-I & $200 \mathrm{mg} / \mathrm{kg}$ b.w. & $98.2 \pm 0.65$ & $70.8 \pm 0.70$ & $50.4 \pm 0.51$ & $40 \pm 0.69$ \\
\hline Group-II & $400 \mathrm{mg} / \mathrm{kg}$ b.w. & $83.6 \pm 0.52$ & $60.4 \pm 0.52$ & $39.2 \pm 0.47$ & $37.2 \pm 0.37$ \\
\hline
\end{tabular}

Values are expressed as Mean \pm SEM $(n=5)$;

$* \mathrm{P}<0.05$ compared with the control group (Dunnett's Test)

\section{Results}

\subsection{Phytochemical Screening}

Preliminary phytochemical screening of the crude extract of Mimosa pudica revealed the presence of tannins, alkaloids, terpenoids and flavonoids.

\subsection{Neuropharmacological Activity Test}

\subsubsection{Hole Cross Test}

The locomotor activity lowering effect was evident for the both doses of 200 and $400 \mathrm{mg} / \mathrm{kg}$ body weight at the $2^{\text {nd }}$ observation $(30 \mathrm{~min})$ and continued up to $3^{\text {rd }}$ and $4^{\text {th }}$ observation (60 and $90 \mathrm{~min}$ ) period. Moreover, the validation of anxiety was carried out by measuring external signs, through hole-cross tests (Table 1).

\subsubsection{Open Field Test}

Open field test showed that the depressing action of the extract was evident from the second observation period in the test animals at the doses of 200 and $400 \mathrm{mg} / \mathrm{kg}$ body weight (Table 2).

\section{Discussion}

The most common human brain disorders are anxiety and its related disorders in individuals with or without dementia. It has been reported that Benzodiazepines (BZDs), barbiturates, and Tricyclic antidepressants (TCA's) have been used for long time to treat anxiety disorders. The serious side effects associated with these drugs, namely rebound insomnia, sedation, muscle relaxation, withdrawal and tolerance, sexual dysfunction, anticholinergic, and antihistaminic effects have limited their use in patients. Buspirone, the non-sedative anxiolytic agent is not effective in a high percentage of patients. It is also associated with tachycardia, palpitation and gastric discomfort [18]. So, herbal plants are good sources to find new remedies for this disorder. In the search for alternative, more specific and feasibly cost effective therapy, research has been directed to investigate natural anxiolytic drugs [19]. Hole cross and open field tests are widely used to assess the neuropharmacological potential of natural products.

A key step in evaluating drug action on CNS is to observe its effect on locomotors activity of the animal. The activity is a measure of the level of excitability of the CNS and this decrease may be closely associated to sedation causing from depression of the central nervous system [20]. We evaluated open field and hole cross tests as the methods of assessing sedative activity. The extract significantly decreased the locomotor activity as shown by the results of the hole cross and open field tests. The locomotor activity lowering effect was evident at the $2^{\text {nd }}$ observation $(30 \mathrm{~min})$ and continued up to $4^{\text {th }}$ observation period $(90 \mathrm{~min}$ ) (Table 1). Furthermore, the justification of sedation was carried out by measuring external signs through hole-cross test. Open field test showed that the depressing action of the extract was also evident from the second observation period in the test animals at the doses of 200 and $400 \mathrm{mg} / \mathrm{kg}$ body weight (Table 2). Mimosa genus was used traditionally for managing anxiety and numerous behavior disorders. Our rudimentary screening for phytochemicals suggests the availability of alkaloids, glycosides, 
flavonoids; tannins may be responsible for neuropharmacological activity. Several phytochemical studies proved that tannins exert sedative activity. Saponins also have potent sedative activity [21]. Furthermore, it is already reported that flavonoids have potent sedative and anxiolytic effects [22]. It has been also reported that flavonoids and alkaloids in many plant species used as folk medicine, exert anxiolytic activity [23]. So, anxiolytic activity of MEMP may be due to the presence of flavonoids and alkaloids.

Pharmacological evaluation of sedative activity proposed that MEMP exerts as GABA-benzodiazepine receptor interaction in the brain. According to hole cross test, the behavioral state of mice diminished the number of hole cross from second to forth observation that confirms the sedative activity of MEMP. In open field test, the locomotion effect of MEMP showed that decreased number of squares crossed by mice was dose-dependent at second $(30 \mathrm{~min})$ to forth $(90 \mathrm{~min})$ observation. These studies also demonstrated that the sedative response of MEMP effect is comparable to that of diazepam.

The sedative activity associated with activation of $\mathrm{GABA}_{\mathrm{A}}$ receptor, extensively found in CNS and benzodiazepines (diazepam) have high-affinity to bind with $\mathrm{GABA}_{\mathrm{A}}$ receptor [24]. Consequently, the observed neuropharmacological effect gives an indication of diazepam like mode of action of MEMP.

\section{Conclusions}

Our experimental findings signify that several phytoconstituents present in MEMP validate sedative activity. These results support the MEMP has similar pharmacological action like diazepam through binding to benzodiazepines site on GABA-BDZ receptor complex. Nevertheless, further advance investigations are required to elucidate the exact mechanism involved in sedative effects and to identify the bio-active compound(s) associated with observed activity in animal behavioral models.

\section{Acknowledgements}

The authors are thankful to the Department of Pharmacy, Stamford University Bangladesh to permit to use the facilities of the Pharmacology and Phytochemistry Laboratory.

\section{Ethics Approval and Consent to Participate}

All the experimental mice were treated following the Ethical Principles and Guidelines for Scientific
Experiments on Animals (1995) postulated by the Swiss Academy of Medical Sciences and the Swiss Academy of Sciences. The Institutional Animal Ethical Committee (SUB/IAEC/17.02) of Stamford University Bangladesh approved all experimental rules.

\section{Competing Interests}

The authors declare that they have no conflict of interests.

\section{Consent for Publication}

Not applicable

\section{Funding}

This research was not funded by any funding agencies. All the studies had been self-funded by author and co-author.

\section{Authors' Contributions}

Md. Lokman Hossain conceived, planned, did literature searches, and performed the experiments. Sharmin Sultana contributed to data analysis, interpreted results and manuscript writing. Md. Lokman Hossain finally edited the manuscript. All authors read and approved the final manuscript.

\section{REFERENCES}

[1] World Health Organisation. The World health report 2001: Mental health: new understanding, new hope. Geneva; 2001 (Accessed on 15 November, 2018).

[2] R. C. Kessler, P. Berglund, O. Demler, R. Jin, D. Koretz, K. R. Merikangas. National comorbidity survey replication, the epidemiology of major depressive disorder: results from the national comorbidity survey replication (NCS-R). J. Am Med Assoc., 289: 3095-3105; 2003.

[3] J. P. Lepine, M. Briley. The increasing burden of depression. Neuropsychiatr. Dis. Treat., 7:3-7; 2011.

[4] I. Hindmarch. Beyond the monoamine hypothesis: mechanisms, molecules and methods. Eur. Psychiatry., 17(3): 294-299; 2002.

[5] S. K. Kulkarni, M. K. Bhutani, M. Bishnoi. Antidepressant activity of curcumin: involvement of serotonin and dopamine system. Psychopharmacology, 201(3): 435-442; 2008.

[6] D. Dhingra, V. Kumar. Evidences for the involvement of monoaminergic and GABAergic systems in 
antidepressant-like activity of garlic extract in mice. Indian J. Pharmacol, 40(4): 175-179; 2008.

[7] F. Donato, M. G. Gomes, A. T. R. Goes, N. Seus, D. Alves, C. R. Jesse. Involvement of the dopaminergic and serotonergic systems in the antidepressant-like effect caused by 4-phenyl-1-(phenylselanylmethyl)-1, 2, 3-triazole. Life Sci., 93(9-11): 393-400; 2013.

[8] C. R. Alves, Jesse. Involvement of the dopaminergic and serotonergic systems in the antidepressant-like effect caused by 4-phenyl-1-(phenylselanylmethyl)-1, 2, 3-triazole. Life Sci., 93(9-11): 393-400; 2013.

[9] A. Dhir, S. K. Kulkarni. Involvement of nitric oxide (NO) signaling pathway in the antidepressant action of bupropion, a dopamine reuptake inhibitor, Eur. J. Pharmacol., 568 (1-3):177-85; 2007.

[10] A. O. Rosa, I. Lin, J. B. Calixto, A. R. S. Santos, A. L. S. Rodrigues. Involvement of NMDA receptors and L-arginine-nitric oxide pathway in the antidepressant-like effects of zinc in mice. Behav. Brain Res., 144(1-2):87-93; 2003.

[11] Z. F. Yu, L. D. Kong, Y. Chen. Antidepressant activity of aqueous extracts of Curcuma longa in mice: Ethnopharmocol, 83: 161; 2002.

[12] D. Antai-Otong. Anti-depressant-induced insomnia: Treatment options. Perspect Psych Care. 40:29-33; 2004.

[13] D. Baldwin, K. Bridgman, C. Buis. Resolution of sexual dysfunction during double-blind treatment of major depression with reboxetine or paroxetine. J. Psychopharmacol, 20:91-96; 2006.

[14] S. Khushi, M. M. Hasan, A. S. M. M. Hossain, M. L. Hossain, S. K. Sadhu. Medicinal Activity of Avicennia officinalis: Evaluation of Phytochemical and Pharmacological Properties. Saudi J. Med. Pharm. Sci., 2 (9):250-255; 2016.

[15] A. Basak, M. L. Hossain, M. N. Parvin. Evaluation of phytochemical and pharmacological activities of Bacopa monnieri (L.). Int. J. Sci. Rep., 2 (10): 242-247; 2016.

[16] W. Jintanaporn, P. Prasert, S. Kittisak, M. Supaporn, S. Bungorn. Evaluation of the anxiolytic and antidepressant effects of alcoholic extract of Kaempferia parviflora in aged rats. Am. J. Agric. Biol. Sci., 2: 94-98; 2007.

[17] Z. Han, T. Shen, H. Lou. Dietary polyphenols and their biological significance. Int. J. Mol. Sci., 8(9): 950-988; 2007.

[18] N. Ahmed, M. M. Rahman, M. R. H. Tareq, M. Ikram, S. Alam. CNS depressant and sedative effects of Andrographis paniculata, PhOL, 2:90-95; 2013.

[19] G. Patro, S. K. Bhattamisra, B. K. Mohanty. Effects of Mimosa pudica L. leaves extract on anxiety, depression and memory. Avicenna J. Phytomed, 6 (6): 696-710; 2016.

[20] M. S. Ali, P. R. Dash, M. Nasrin. Study of sedative activity of different extracts of Kaempferia galanga in Swiss albino mice, BMC Complementary Altern. Med., 15: 158, DOI 10.1186/s12906-015-0670-z; 2015.

[21] H. Wagner, S. Ott, K. Jurcic, J. Morton, A. Neszmelyi. Chemistry, 13C-NMR study and pharmacology of two saponins from Colubrina asiatica. Planta Med., 48:136-141, DOI: 10.1055/s-2007-969908; 1983.

[22] H. Haberlein, K. Tschiersch, H. Schafer. Flavonoids from Leptospermum scoparium with affinity to the benzodiazepine receptor characterized by structure activity relationships and in-vivo studies of a plant extract. Die Pharmazie, 49:912-922; 1994.

[23] M. Rabbani, S. E. Sajjadi, A. Mohammadi. Evaluation of the anxiolytic effect of Nepeta persica Boiss. In mice, J. Evidence-Based Complementary Altern. Med., 5(2): $181-186 ; 2008$

[24] R. Sankar. GABA $A_{A}$ receptor physiology and its relationship to the mechanism of action of the 1,5-benzodiazepine clobazam. CNS drugs, 26:229-244; 2012. 